\title{
Cost-effectiveness of adding rituximab to fludarabine and cyclophosphamide for treatment of chronic lymphocytic leukemia in Ukraine
}

This article was published in the following Dove Press journal:

Cancer Management and Research

25 August 2015

Number of times this article has been viewed

\author{
Olena Mandrik' \\ Isaac Corro Ramos ${ }^{2}$ \\ Saskia Knies ${ }^{1,3}$ \\ Maiwenn $\mathrm{Al}^{1,2}$ \\ Johan L Severens ${ }^{1,2}$ \\ 'Institute of Health Policy and \\ Management, Erasmus University \\ Rotterdam, Rotterdam, the \\ Netherlands; ${ }^{2}$ Institute of Medical \\ Technology Assessment (iMTA), \\ Erasmus University Rotterdam, \\ Rotterdam, the Netherlands; \\ ${ }^{3}$ National Health Care Institute, \\ Diemen, the Netherlands
}

\begin{abstract}
The aim of this study was to assess the cost-effectiveness, from a health care perspective, of adding rituximab to fludarabine and cyclophosphamide scheme (FCR versus FC) for treatment-naïve and refractory/relapsed Ukrainian patients with chronic lymphocytic leukemia. A decision-analytic Markov cohort model with three health states and 1-month cycle time was developed and run within a life time horizon. Data from two multinational, prospective, open-label Phase 3 studies were used to assess patients' survival. While utilities were generalized from UK data, local resource utilization and disease-associated treatment, hospitalization, and side effect costs were applied. The alternative scenario was performed to assess the impact of lower life expectancy of the general population in Ukraine on the incremental cost-effectiveness ratio (ICER) for treatment-naïve patients. One-way, two-way, and probabilistic sensitivity analyses were conducted to assess the robustness of the results. The ICER (in US dollars) of treating chronic lymphocytic leukemia patients with FCR versus FC is US $\$ 8,704$ per quality-adjusted life year gained for treatment-naïve patients and US\$11,056 for refractory/relapsed patients. When survival data were modified to the lower life expectancy of the general population in Ukraine, the ICER for treatment-naïve patients was higher than US\$13,000. This value is higher than three times the current gross domestic product per capita in Ukraine. Sensitivity analyses have shown a high impact of rituximab costs and a moderate impact of differences in utilities on the ICER. Furthermore, probabilistic sensitivity analyses have shown that for refractory/relapsed patients the probability of FCR being cost-effective is higher than for treatment-naive patients and is close to one if the threshold is higher than US\$15,000. State coverage of rituximab treatment may be considered a cost-effective treatment for the Ukrainian population under conditions of economic stability, cost-effectiveness threshold growth, or rituximab price negotiations.
\end{abstract}

Keywords: cost-effectiveness, rituximab, leukemia, Ukraine

\section{Introduction}

Chronic lymphocytic leukemia (CLL) is a progressive oncological disease characterized by the clonal proliferation and accumulation of neoplastic B lymphocytes in the blood, bone marrow, lymph nodes, and spleen. According to the Ukrainian National Cancer Register ${ }^{1}$ the total morbidity rate for patients with diagnosed leukemia was 7.8 per 100,000 people. No national Ukrainian statistical data on CLL prevalence are available; however, if we assume the same distribution as in the US exists for the four major types of leukemia, up to 3.7 per 100,000 people are estimated to be CLL related. ${ }^{2}$ The clinical course of this disease can be highly diverse and dependent on many factors, such as stage of the disease by Rai (from 0 to IV) and Binet (from A to C), chromosomal abnormalities, or mutations of the immunoglobulin heavy variable chain gene. ${ }^{3-5}$
Correspondence: Olena Mandrik Institute of Health Policy and Management, Erasmus University Rotterdam, PO Box 1738, 3000 DR

Rotterdam, the Netherlands

$\mathrm{Tel}+31 \quad 104088525$

Fax +3। 104089094

Email olena.dem@gmail.com 
With the exception of blood band marrow transplantationwhich has significant limitations by age and comorbidities CLL remains an incurable condition. According to the national treatment protocol in Ukraine ${ }^{5}$ there is a number of treatment options for CLL patients. Besides the "watch and wait" strategy for patients with the asymptomatic state of CLL, monotherapies are currently available: cytotoxic drugs including alkylating agents (chlorambucil, cyclophosphamide, and bendamustine), antimetabolites or purine analogs (fludarabine or cladribine), mitoxantrone (an anthracycline) and prednisolone (a corticosteroid), as well as a number of therapeutic chemotherapy combination schemes. ${ }^{3,5}$ One of the most frequently prescribed schemes for CLL patients treated in specialized hospitals of Ukraine is a fludarabine and cyclophosphamide scheme (FC). ${ }^{6}$

Rituximab, a monoclonal antibody that targets the CD20 cell surface antigen, is recommended for use in combination with chemotherapy for both treatment-naïve patients, refractory patients (those who experienced treatment failure or disease progress within 6 months of the last treatment) or patients who relapsed (those who experienced a response to therapy, but progressed after 6 or more months). Despite being one of the most expensive drugs used in CLL treatment in Ukraine, rituximab was included in the state tender purchases the previous years. ${ }^{6,7}$ Adding rituximab to FC (FCR) has been shown to be a promising medical product according to clinical trial data on both previously treated and untreated CLL patients. ${ }^{4,8}$

The cost-effectiveness of FCR versus FC in treatment of naïve or refractory/relapsed patients was previously confirmed in Spain, the US, and the UK..$^{9-11}$ In Spain the incremental cost-effectiveness ratio (ICER) was $€ 19,343$ per quality-adjusted life year (QALY) gained for the first-line treatment and $€ 24,781$ for the second-line treatment over a 10 -year horizon. ${ }^{9}$ In the US study the ICER was US $\$ 23,530$ per QALY considering a third-party payer and US\$31,513 per QALY considering a societal perspective over the life time horizon. ${ }^{10}$ In the UK rituximab was also considered to be a cost-effective option with an ICER of $£ 13,189$ per QALY for FCR versus FC in the treatment of naïve patient population; however its combination with other chemotherapy agents was not recommended by the National Institute for Health and Care Excellence. ${ }^{11}$

To the best of our knowledge no economic evaluation on rituximab use was performed in Ukraine, nor any other country of the Central and Eastern European or former Soviet region. Because of differences in treatment practice, perspectives, unit costs (including hospitalization), and demographic characteristics (both patients and general population), generalizability to Ukraine of the economic evaluations mentioned above is not possible. While no costeffectiveness threshold has been established in Ukraine, the World Health Organization (WHO) considers technologies with a threshold of less than one GDP per capita to be very cost-effective, and those with a threshold of less than three GDP per capita to be cost-effective. ${ }^{12}$ In 2013 the GDP per capita in Ukraine was equal to US\$3,900, according to data of the World Bank. ${ }^{13}$

In sum, the aim of this study was to assess, from a health care perspective using a life time horizon, the costeffectiveness of FCR compared to FC for treatment-naïve and refractory/relapsed Ukrainian CLL patients.

\section{Methods}

\section{Framework/structure of the model}

Two decision-analytic Markov cohort models with the same structure were developed in Microsoft ${ }^{\circledR}$ Excel 2007 to assess the incremental costs and benefits associated with FCR. These models were run on two populations using data from two randomized controlled trials, one with treatment-naïve and one with refractory/relapsed patients. Three health states were defined in the models with a cycle time of 1 month: 1) stable or progression-free state; 2) disease-progressed state; and 3) death. Assessment of the incremental costs and benefits from a health care perspective was conducted using a life time horizon. QALYs comprised the main outcome in both models with uniform $3 \%$ discounting for both costs and effects. ${ }^{14}$

\section{Target population}

We considered the modeled cohort of treatment-naïve patients to be identical to the trial population from a published prospective, open-label, Phase 3 study on 817 randomly assigned (1:1) patients carried out in 190 centers in eleven countries. Enrolled in this study were treatment-naïve patients diagnosed with immunophenotypically confirmed CLL in Binet stage C ( $31 \%$ in FC and $31 \%$ in FCR) or those with confirmed active disease in Binet stages A (5\% in FC and $4 \%$ in FCR) or B (63\% in FC and $64 \%$ in FCR). Mean age of patients was 61 years and $74 \%$ were males. Eastern Cooperative Oncology Group (ECOG) performance status of 0 was reported in $58 \%$ of FC and $56 \%$ of FCR groups. ${ }^{4}$ (ECOG performance status is the criteria used to assess how the disease affects daily living abilities of patients, where " 0 " is a fully active person and " 5 " is dead [http:// www.ecog.org/]). 
The modeled cohort of refractory/relapsed patients was considered to be identical to the trial population from an international, multicenter, open-label, Phase 3 study on 552 randomly assigned (1:1) patients carried out in 88 centers in 17 countries. Patients who had received one prior line of therapy, such as single-agent chlorambucil (or combined with prednisone/prednisolone), single-agent fludarabine (or another nucleoside analog), or an alkylator containing combination regimen, but not an alkylator/nucleoside analog combination, were enrolled in that study. The distribution of CLL patients by confirmed Binet stages in this trial was as follows: stage $\mathrm{C}$ ( $31 \%$ in $\mathrm{FC}$ and $31 \%$ in FCR), stage $\mathrm{A}$ (11\% in FC and 9\% in FCR), and stage B (58\% in FC and $60 \%$ in FCR). Mean age of patients was 62 years in FC and 63 in FCR groups, 66\% (FC) and 68\% (FCR) were males. An ECOG performance status of 0 was reported in $59 \%$ of FC and $61 \%$ of FCR groups. ${ }^{8}$

\section{Treatment and treatment effect}

According to trial data ${ }^{4,8}$ and national clinical guidelines, CLL patients on FCR should receive the following doses of drugs during each cycle: fludarabine $\left(25 \mathrm{mg} / \mathrm{m}^{2} / \mathrm{d}\right)$, cyclophosphamide $\left(250 \mathrm{mg} / \mathrm{m}^{2} / \mathrm{d}\right)$ for 3 days, rituximab $\left(375 \mathrm{mg} / \mathrm{m}^{2}\right.$ on day one of the first cycle and $500 \mathrm{mg} / \mathrm{m}^{2}$ on day one of subsequent cycles). In the model, dose-per-patient was calculated using an average body surface among the Ukrainian population $\left(1.86 \mathrm{~m}^{2}\right)$. We considered that the Markov cohort population did not receive full courses of therapy similar to the trial population, ${ }^{4,8}$ so the final average doses of each drug were adjusted to the average consumed doses (by treatment adherence in trials) (Table 1).

\section{Survival data}

Overall survival and progression-free survival (PFS) were retrieved from the trials' publications presenting Kaplan-Meier plots. ${ }^{4,8}$ The reported observation period equal to 61 months for treatment-naïve patients and to 57 months for previously-treated patient (52 months for PFS during FC treatment) was chosen. ${ }^{4,8}$ There was no information available on characteristics of Ukrainian CLL patients by Binet stages and ECOG performance status. At the same time, by sex and age distribution Ukrainian CLL patients were similar to trial populations selected as clinical data sources. ${ }^{4,6,8}$ Two parametric extrapolation methods were applied. A Weibull model was selected to incorporate monotonic hazards, while a log-logistic model was selected as an alternative to incorporate non-monotonic hazards. The model that provides the closest parametric estimation was selected for cohort survival assessment.

\section{Costs}

In line with recommendations of the International Society For Pharmacoeconomics and Outcomes Research taskforce report on transferability, ${ }^{15}$ unit costs and resource utilization were retrieved from local sources. From the health care perspective, the following costs were included in the model: initial therapy costs, hospitalization costs, adverse events costs, and salvage costs (Table 1). Unit drug costs were included in the deterministic model by the most frequently prescribed trade names. ${ }^{6}$ Unit drug prices were retrieved from the website of Ukraine's Ministry of Health. ${ }^{16}$ Costs of grades 3 and 4 adverse events reported with a frequency greater than or equal to $5 \%$ were accounted for in the model calculations. Opinions of clinical experts from specialized institutions of Ukraine and hospital records were used to define the most frequently prescribed treatment schemes for these conditions A previously published costing study in Ukraine was used to assess costs of salvage treatment. ${ }^{6}$ Because of data obsolescence, these costs were considered to grow by the consumer price index for pharmaceuticals and health care for the last 4 years (5.7\%). Additionally, the model took into consideration the monthly growth in costs for salvage treatment proportional to an average monthly consumer price index for pharmaceuticals and health care $(0.11875 \%) .{ }^{17}$ Data of specialized hospitals in Ukraine were used to determine an average duration of hospitalization due to a relapse, as well as daily costs of hospital stay excluding pharmaceutical treatment. ${ }^{6}$ Similar to pharmaceutical treatments, hospital stay unit costs were considered to grow proportionally to an average consumer price index for pharmaceuticals and health care. The exchange rate of the National Bank of Ukraine on June 4, 2014 (11,833 Ukrainian Hryvnia per US\$) was used in all calculations.

\section{Utilities}

No country-specific utility data were available for CLL patients, nor for the general Ukrainian population, therefore, utilities of health states associated with CLL treatment (values of 0.78 for the progression-free or stable disease state and 0.68 for the progressed disease) were assumed generalizable from the UK. ${ }^{18}$

\section{Sensitivity analyses and data transferability}

We used sensitivity analyses to address uncertainty in the defined input parameters specific for Ukraine and those generalized from other populations. Using univariate analyses we assessed the impact of variations in rituximab costs, 


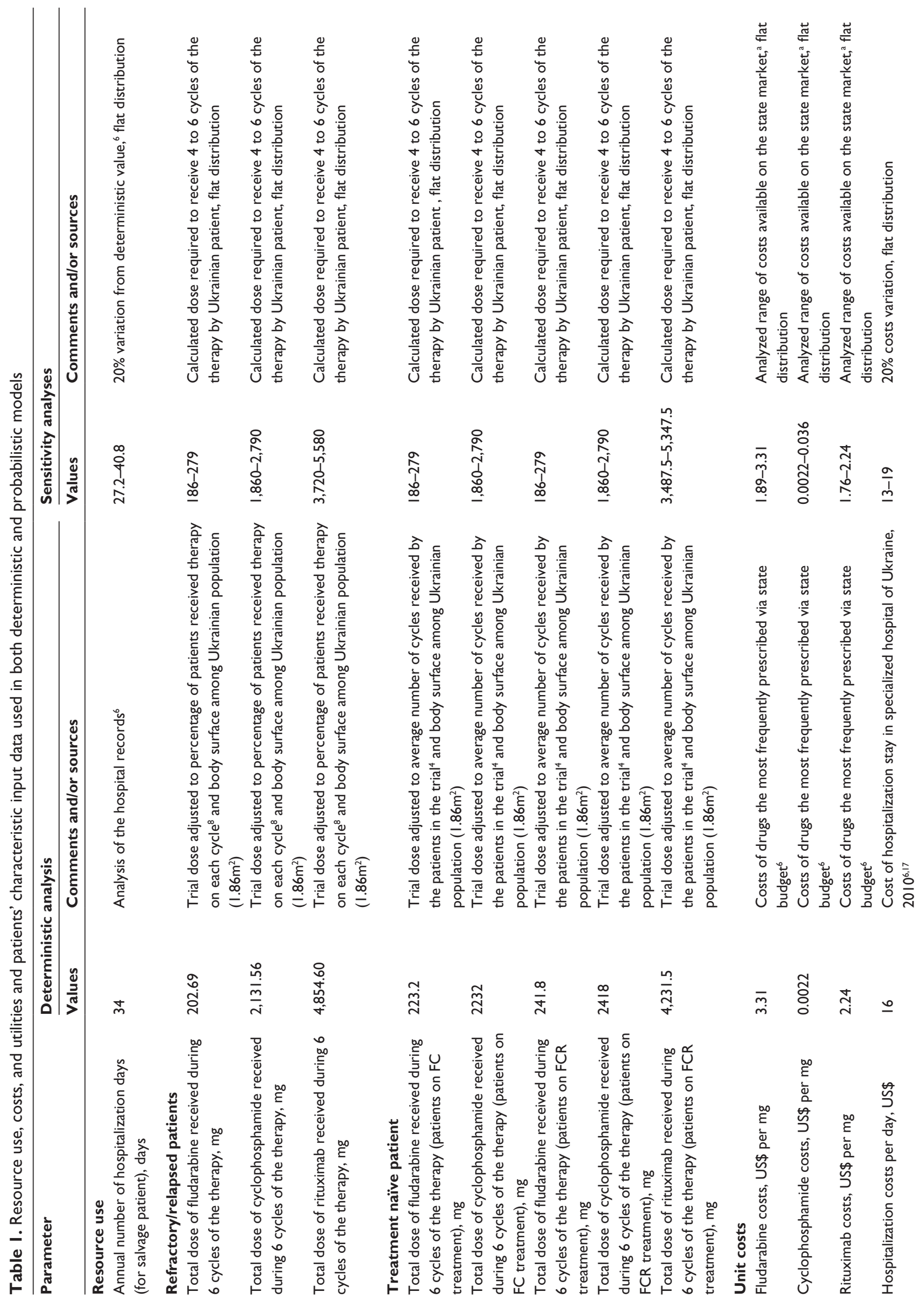




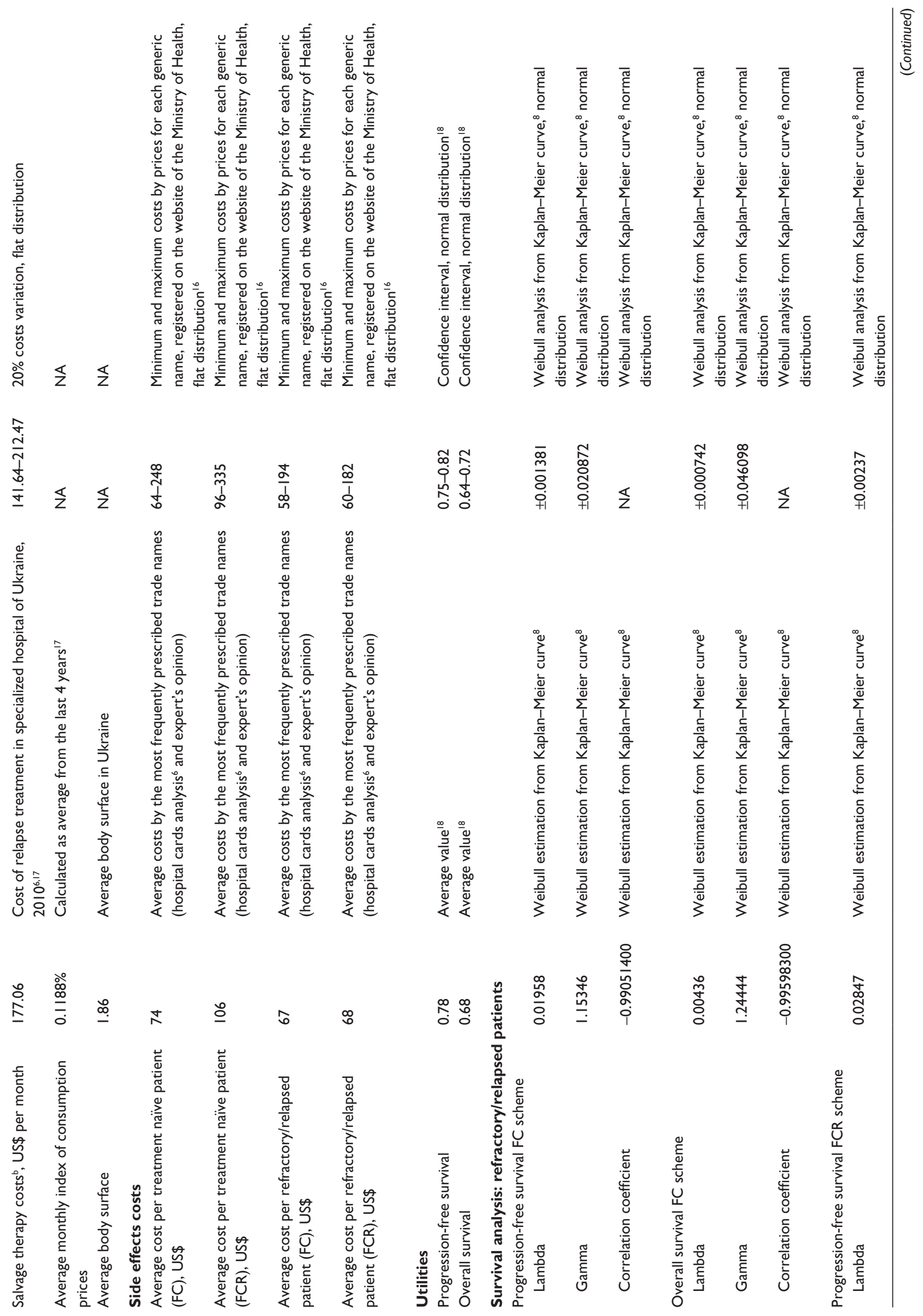




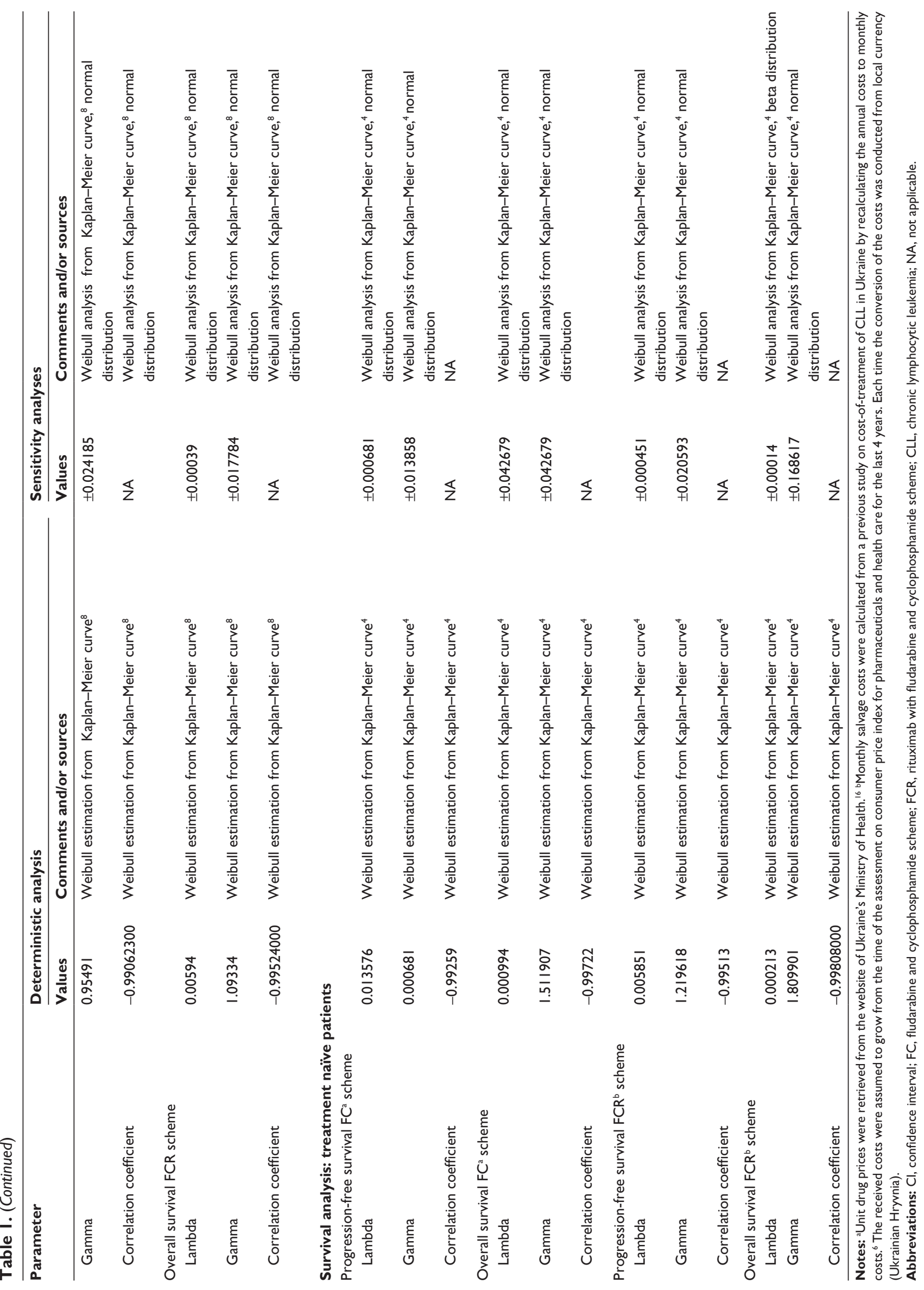


hospitalization costs, salvage treatment costs, costs of side effects, average monthly index of consumption prices and discount rates. Multivariate analysis was applied because the UK data on utilities for different cancer states were generalized to the Ukrainian population for whom local data was absent.

The two trials used a multinational sample as a source of survival data for Markov cohort CLL patients., ${ }^{4,8}$ Although the patient's country of enrollment in the trials was not reported, we assume that most were enrolled in countries with developed economies, where life-duration of the general population differs from those in Ukraine. Therefore we report an alternative scenario with Ukraine-specific mortality rate for non-CLL related causes to assess the impact of this parameter on the ICER. For this the sex- and age-specific difference in death probability among general population in the US and Ukraine was calculated. For this the difference in death probabilities between US and Ukrainian males and females of different age was calculated first using national statistical data. ${ }^{19,20}$ Afterward, the death probability among the population identical to the cohort by sex and age characteristics was retrieved. As the next step the overall survival and PFS from the trial were added to the positive or negative coefficient of the difference in mortality depending on the patient's age at initiation of therapy. The survival analysis with Weibull extrapolation was performed on the received adjusted data to ensure higher reliability of the received results.

Additional scenario analyses were conducted to assess the impact of survival analysis on cost-effectiveness results. We varied duration of patients' observation period in the trials and assessed impact of these changes on the results of survival analysis and economic evaluations. Probabilistic sensitivity analyses with 5,000 runs were conducted to define overall uncertainty of the model. Both deterministic and probabilistic model parameters are presented in Table 1.

\section{Results}

Treatment with rituximab resulted in both a longer expected survival and a gain in QALYs compared to the standard therapy (Table 2). The gain in expected number of life years was 1.60 for both treatment-naïve and refractory/relapsed patients treated with the FCR versus FC in the base-case scenario. Associated costs were higher with FCR rather than FC treatment in the base case and all alternative scenarios (Table 2). The difference in QALYs gained and costs was smaller in the scenarios where survival analysis was conducted on the trial data with the longer follow-up (and the opposite). When survival data on treatment-naïve patients were extrapolated to 65 months, the incremental value of QALYs became negative. There was a smaller observed difference in both QALYs and costs for the FC and FCR treatment-naïve population, when adjustment to the expected higher mortality among the general population of Ukraine was conducted.

For every expected QALY gained, US\$8,704 will be needed in the base-case scenario for state coverage of treatment-naïve patients, which can be considered a costeffective option. The ICER of treating refractory/relapsed patients with FCR is close to the cost-effectiveness threshold within the base-case scenario (ICER US\$11,056; threshold of three GDP per capita is US\$11,700). The ICER of FCR use for treatment-naïve patients will be close to US\$13,000 if a higher mortality among the general population in Ukraine is considered in the survival analysis. This ICER for treatmentnaïve patients is above the theoretical cost-effectiveness threshold in Ukraine.

As can be seen from Table 3, an increase in the average consumer price index and discount rate caused a higher

Table 2 Cost-effectiveness analysis of adding rituximab to fludarabine plus cyclophosphamide scheme in treatment-naïve and refractory/ relapsed patients: base-case and scenario analyses

\begin{tabular}{llll}
\hline & Cost difference & QALY difference & ICER (US $\$ / Q A L Y)$ \\
\hline Treatment-naïve patients & & & \\
Base-case scenario FCR versus FC & US $\$ 10,827$ & 1.24 & US $\$ 8,704$ \\
Scenario I: Ukraine-specific mortality among general population & US $\$ 8,022$ & 0.62 & US $\$ 12,897$ \\
Scenario 2: 56 months survival data & US $\$ 16,88$ I & 2.61 & US $\$ 6,475$ \\
Scenario 3: 60 months survival data & US $\$ 15,204$ & 2.22 & US $\$ 6,851$ \\
Scenario 4: 62 months survival data & US $\$ 7,677$ & 0.62 & US $\$ 12,343$ \\
Scenario 5: 65 months extrapolated survival data & US $\$ 4,786$ & -0.83 & Dominated \\
Treatment-experienced patients & & & \\
Base-case scenario FCR versus FC & US $\$ 13,081$ & 1.18 & US $\$ 1 I, 065$ \\
Scenario I: 52 months survival data, ICER (US\$ per QALY) & US $\$ 14,660$ & 1,53 & US $\$ 9,557$ \\
\hline
\end{tabular}

Abbreviations: FC, fludarabine and cyclophosphamide scheme; FCR, rituximab with fludarabine and cyclophosphamide scheme; QALY, quality-adjusted life year; ICER, incremental cost-effectiveness ratio. 
Table 3 Univariate and multivariate sensitivity analysis: impact of costs variations on cost-effectiveness results

\begin{tabular}{|c|c|c|c|c|}
\hline \multirow[t]{2}{*}{ Parameters of variation and values } & \multicolumn{2}{|c|}{$\begin{array}{l}\text { ICER treatment-naïve } \\
\text { patients }\end{array}$} & \multicolumn{2}{|c|}{$\begin{array}{l}\text { ICER treatment-experienced } \\
\text { patients }\end{array}$} \\
\hline & US\$/QALY & $\begin{array}{l}\% \text { of change } \\
\text { from base ICER }\end{array}$ & US\$/QALY & $\begin{array}{l}\% \text { of change } \\
\text { from base ICER }\end{array}$ \\
\hline \multicolumn{5}{|c|}{ Average monthly index of consumption prices } \\
\hline $0 \%$ & US $\$ 8,501$ & $2 \%$ & US\$10,677 & $4 \%$ \\
\hline $0.2375 \%$ (double from deterministic value) & US $\$ 8,907$ & $-2 \%$ & US\$1I,453 & $-4 \%$ \\
\hline \multicolumn{5}{|l|}{ Discounting, annual } \\
\hline $0 \%$ & US $\$ 6,904$ & $21 \%$ & US $\$ 8,754$ & $21 \%$ \\
\hline $5 \%$ & US\$10,194 & $-17 \%$ & US\$13,010 & $-18 \%$ \\
\hline $10 \%$ & US $\$ 15,04 \mid$ & $-73 \%$ & US\$19,494 & $-76 \%$ \\
\hline \multicolumn{5}{|c|}{ Multivariate (discounting and average monthly index of consumption prices) } \\
\hline $0 \%$ & US $\$ 6,645$ & $24 \%$ & US $\$ 8,297$ & $25 \%$ \\
\hline Doubled from deterministic value & US\$1I,I84 & $-28 \%$ & US $\$ 14,440$ & $-31 \%$ \\
\hline \multicolumn{5}{|l|}{ Rituximab costs } \\
\hline $50 \%$ from deterministic costs & US\$4,538 & $48 \%$ & US\$6,47I & $42 \%$ \\
\hline $25 \%$ from deterministic costs & US $\$ 2,455$ & $72 \%$ & US $\$ 4,173$ & $62 \%$ \\
\hline $120 \%$ from deterministic costs & US\$10,37I & $-19 \%$ & US\$12,903 & $-17 \%$ \\
\hline \multicolumn{5}{|l|}{ Hospitalization costs } \\
\hline $50 \%$ from deterministic costs & US $\$ 8,673$ & $0 \%$ & US\$10,895 & $2 \%$ \\
\hline $25 \%$ from deterministic costs & US $\$ 8,657$ & $1 \%$ & US $\$ 10,810$ & $2 \%$ \\
\hline $120 \%$ from deterministic costs & US $\$ 8,717$ & $0 \%$ & US\$1 $\$, 133$ & $-1 \%$ \\
\hline \multicolumn{5}{|l|}{ Salvage therapy costs } \\
\hline $50 \%$ from deterministic costs & US $\$ 8,563$ & $2 \%$ & US\$10,298 & $7 \%$ \\
\hline $25 \%$ from deterministic costs & US $\$ 8,492$ & $2 \%$ & US $\$ 9,914$ & $10 \%$ \\
\hline I $20 \%$ from deterministic costs & US $\$ 8,76 \mathrm{I}$ & $-1 \%$ & US\$11,372 & $-3 \%$ \\
\hline \multicolumn{5}{|l|}{ Side effects costs (FCR) } \\
\hline $50 \%$ from deterministic costs & US $\$ 8,662$ & $0 \%$ & US\$11,036 & $0 \%$ \\
\hline $25 \%$ from deterministic costs & US $\$ 8,640$ & $1 \%$ & US\$1I,022 & $0 \%$ \\
\hline $120 \%$ from deterministic costs & US $\$ 8,722$ & $0 \%$ & US\$1I,076 & $0 \%$ \\
\hline \multicolumn{5}{|l|}{ Utilities } \\
\hline $\begin{array}{l}\text { Utility score } 0.78 \text { for progressed state } \\
\text { and } 0.88 \text { for progression-free state }\end{array}$ & US\$7,7I0 & $11 \%$ & US $\$ 9,744$ & $12 \%$ \\
\hline $\begin{array}{l}\text { Utility score } 0.58 \text { for progressed state } \\
\text { and } 0.68 \text { for progression-free state }\end{array}$ & US\$9,993 & $-15 \%$ & US $\$ 12,800$ & $-16 \%$ \\
\hline $\begin{array}{l}\text { Utility score } 0.58 \text { for progressed state } \\
\text { and } 0.88 \text { for progression-free state }\end{array}$ & US\$7,786 & $11 \%$ & US $\$ 10,838$ & $2 \%$ \\
\hline
\end{tabular}

Abbreviations: FCR, rituximab with fludarabine and cyclophosphamide scheme; QALY, quality-adjusted life year; ICER, incremental cost-effectiveness ratio.

ICER for both treatment-naïve and refractory/relapsed patient populations. Similarly, multivariate analyses with zero values for both discounting and average monthly index of consumer prices resulted in ICERs of US\$6,645 and US\$8,297, respectively. Rituximab cost was the only cost parameter having a significant impact on the ICER in both populations. Changes in utilities had a moderate impact on cost-effectiveness results.

The results of probabilistic sensitivity analysis showed a high probability for FCR treatment to be cost-effective for both treatment-naïve patients (cost difference US $\$ 13,118$, standard deviation [SD] US\$8,079; QALYs difference 2.21, SD 1.78; ICER US\$5,938) and refractory/relapsed patients (cost difference US\$14,290, SD US\$2,455; QALYs difference 1.68 , SD 0.45 ; ICER US $\$ 8,485$ ) with the threshold of
US $\$ 11,000$ (Figure 1). As the threshold value increases, the probability of FCR being cost-effective is higher for refractory/relapsed patients. In particular, when the threshold is higher than US\$15,000, the probability of FCR being costeffective converges to one for refractory/relapsed patients and to 0.80 for treatment-naïve patients (Figure 2).

\section{Discussion}

Neither for treatment-naïve nor for refractory patients is FCR a cost-effective option when using a threshold of US\$3,900. ${ }^{13}$ However, use of FCR can still be considered a cost-effective option when using the theoretical threshold of three times the GDP per capita in Ukraine. As such, we conclude that providing this drug should not be considered the highest priority, but should depend on budget availability. This conclusion 


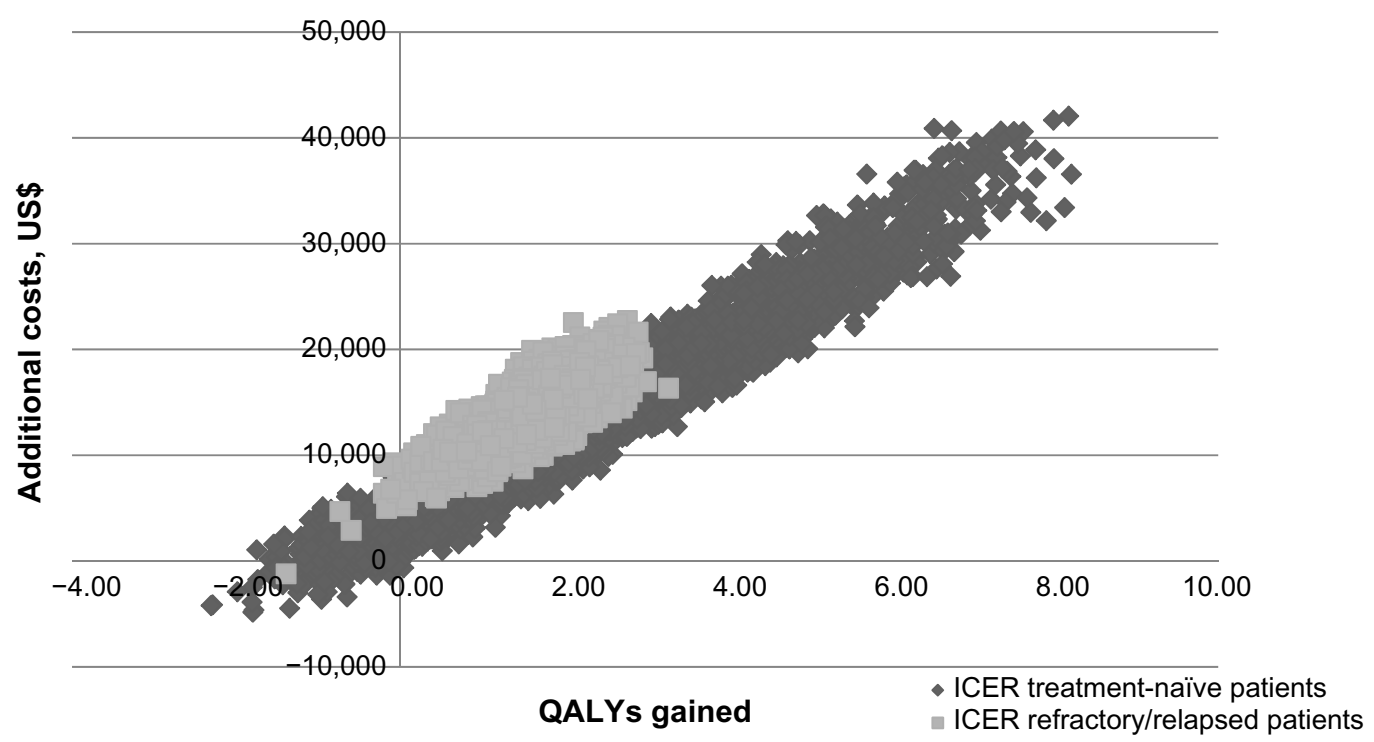

Figure I Cost-effectiveness plane: adding rituximab to treatment of naïve and refractory/relapsed patients.

Abbreviations: QALYs, quality-adjusted life years; ICER, incremental cost-effectiveness ratio.

is supported by the decision uncertainty demonstrated by the sensitivity analyses; thus, the state coverage of this drug for both treatment-naïve and refractory/relapsed population remains a possibility to be argued.

The Ukrainian Ministry of Health purchases rituximab annually for CLL patients' needs without recommendations on its actual use. Nearly US $\$ 1.4$ million of the state budget was spent on rituximab purchase in 2013. ${ }^{7}$ However, based on current evidence there is a higher rationality for it to be provided for the treatment-naïve patient population, rather than for refractory/relapsed patients. At the same time, if the theoretical threshold will become higher as a result of an improving Ukrainian economy, then coverage of refractory/ relapsed patients is likely to become a more cost-effective option than that for the treatment-naïve population, an outcome primarily related to the higher stability of the results. On the other hand, in an unstable economic environment, FCR treatment of refractory/relapsed patients may not be a cost-effective option from a health care perspective, taking into account that any increase in the discount rate, treatment

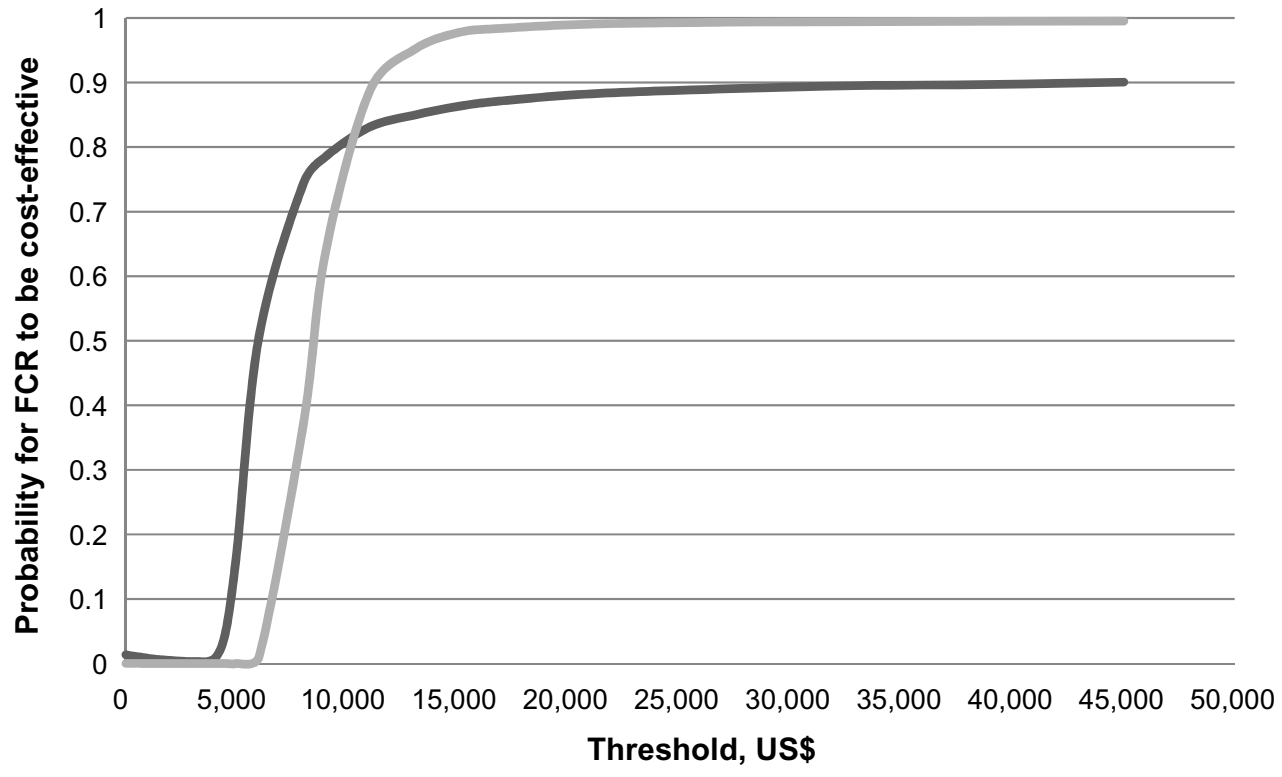

Treatment-naïve patients $\longrightarrow$ Refractory/relapsed patients

Figure 2 Cost-effectiveness acceptability curves.

Abbreviation: FCR, rituximab with fludarabine and cyclophosphamide scheme. 
costs, or inflation rate (index of consumer prices) leads to an ICER estimate close to or above the value of the theoretical threshold. Because rituximab cost was the most influential parameter, price negotiation may be applied to ensure that state spending on this treatment is rational.

Because multinational clinical data were used for both models, we were concerned with how representative the trial population would be for Ukraine. While published data were used to populate the models, the cohort population in both models was not different by sex and age characteristics from both trial population and profiles of CLL patients in Ukraine in terms of mean age of naïve patients (60.3), age of refractory/ relapsed patient (62.8), and the fact that $67 \%$ of patients were male. ${ }^{6}$ Moreover, we considered that because of differences in age at diagnosis between different countries, if trial data were primarily retrieved from economically developed countries, the mortality from other causes in CLL trial population may be different from those in Ukraine. We conclude that if such a case exists, then it is doubtful that the use of rituximab in CLL population in Ukraine will be cost-effective.

As stated in the introduction, until now the costeffectiveness of rituximab was assessed only in health care settings of economically more developed countries, such as the US, ${ }^{10}$ the UK, ${ }^{11}$ and Spain. ${ }^{9}$ While all studies used threestage models, the perspectives, model durations, and data extraction approaches differed. Methodological differences and non-generalizability of data limited transferring results of these studies to Ukraine. The third-party perspective is not applicable for Ukraine and, because of the significant number of assumptions, ${ }^{10}$ the societal perspective also is not considered. Additionally, the use of parametric extrapolation methods for survival analysis instead of raw trial data was considered important because of the high impact of survival parameters on the ICER. While no relation between the country's income expressed by GDP per capita and the costeffectiveness of FCR in comparison to FC has been shown in prior research, ${ }^{9-11}$ in our study we see a significant difference in the values of the ratios observed. We also note an important similarity between our study and one conducted in the Spanish health care setting; ${ }^{9}$ namely, treating treatmentnaïve patients with FCR appeared to be more cost-effective than for refractory/relapsed patients.

\section{Limitations}

As a limitation we should point out that data pertaining to the trial population and the mortality rate from non-CLL causes among trial populations were not available, thus may not correspond to the Ukrainian population. Moreover, Ukrainian costs data are limited and based on one study assessment.

\section{Conclusion}

State coverage of rituximab treatment may not be considered a cost-effective treatment option for the Ukrainian population compared to current care; however, it may become cost-effective under conditions of economic stability, costeffectiveness threshold growth or rituximab price negotiations. Taking into account the WHO recommendations on cost-effectiveness thresholds and current GDP per capita in Ukraine, state coverage of FCR for treatment-naïve patients is more economically argued than that for refractory/relapsed patients.

\section{Acknowledgment}

Olena Mandrik is affiliated with Erasmus University Rotterdam, Institute of Health Policy and Management by means of a PhD-hospitality agreement.

\section{Disclosure}

Olena Mandrik has worked for different pharmaceutical companies, none of which is related to the production of the study drug or to the study itself. The authors have no other conflict of interests to declare.

\section{References}

1. Fedorenko ZP, Goulak LO, Gorokh YL, et al. Рак в Україні, 2011-2012. Захворюваність, смертність, показники діяльності онкологічної служби. [Cancer in Ukraine, 2011-2012. Incidence, mortality, activities of oncological service]. Kyiv: National Cancer Institute of Ukraine; 2013. Ukrainian.

2. Leukemia and lymphoma society. Facts spring 2014-2015. Leukemia and lymphoma society. Available from: http://www.lls.org/content/nationalcontent/resourcecenter/freeeducationmaterials/generalcancer/pdf/ facts.pdf. Accessed April 22, 2015.

3. Dretzke J, Barton P, Kaambwa B, et al. Rituximab for the treatment of relapsed/refractory chronic lymphocytic leukaemia. Health Technol Assess. 2010;14(Suppl 2):19-26.

4. Hallek M, Fischer K, Fingerle-Rowson G, et al. Addition of rituximab to fludarabine and cyclophosphamide in patients with chronic lymphocytic leukaemia: a randomised, open-label, phase 3 trial. Lancet. 2010; 376(9747):1164-1174.

5. Ministry of Health of Ukraine. Order of the Ministry of Health of Ukraine \#647. Про затвердження клінічних протоколів надання медичної допомоги хворим зі спеціальності «Гематологія». [About approval of the clinical protocols on medical help provision for patients on specialty "Hematology"]. Ministry of Health; 2010. Available from: http://moz. gov.ua/ua/portal/dn_20100730_647.html. Accessed September 17, 2014. Ukrainian.

6. Mandrik O, Carro Ramos I, Zalis'ka O, Gaysenko A, Severens JL. Cost of drugs treatment for chronic lymphocytic leukemia in Ukraine. Value in Health Regional Issues. 2013;3:205-209. 
7. Ministry of Health of Ukraine. Order of the Ministry of Health of Ukarine \#358. Розподіл лікарських засобів для лікування онкогематологічних хворих, закуплених у централізованому порядку за кошти Державного бюджету України на 2013 рік за бюджетною програмою КПКВК 2301400. [About distribution of drugs for treatment of oncohematologic patients, that were purchased within the centralised order by the costs of State Budget of Ukraine in 2013]. Ministry of Health; 2013. Available from: http://www.moz. gov.ua/docfiles/dod358_2013.pdf. Accessed September 17, 2014. Ukrainian.

8. Robak T, Dmoszynska A, Solal-Céligny P, et al. Rituximab plus fludarabine and cyclophosphamide prolongs progression-free survival compared with fludarabine and cyclophosphamide alone in previously treated chronic lymphocytic leukemia. J Clin Oncol. 2010;28(10):1756-1765.

9. Casado LF, García Marco JA, Gilsanz F, et al. Evaluación económica de rituximab en combinación con fludarabina y ciclofosfamida en comparación con fludarabina y ciclofosfamida en el tratamiento de la leucemia linfática crónica. [Economic evaluation of rituximab added to fludarabine plus cyclophosphamide versus fludarabine plus cyclophosphamide for the treatment of chronic lymphocytic leukemia]. Gac Sanit. 2011;25(4):274-281. Spanish.

10. Hornberger J, Reyes C, Shewade A, et al. Cost-effectiveness of adding rituximab to fludarabine and cyclophosphamide for the treatment of previously untreated chronic lymphocytic leukemia. Leuk Lymphoma. 2012;53(2):225-234.

11. Main C, Pitt M, Moxham T, Stein K. The clinical effectiveness and cost-effectiveness of rituximab for the first-line treatment of chronic lymphocytic leukaemia: an evidence review of the submission from Roche. Health Technol Assess. 2010;14(Suppl 2):27-32.

12. World Health Organization. Cost effectiveness and strategic planning (WHO-CHOICE). Cost-effectiveness thresholds. WHO. Available from: http://www.who.int/choice/costs/CER_thresholds/en/. Accessed April 22, 2015
13. World Bank. GDP per capita (current US\$). World Bank national accounts data, and OECD National Accounts data files. Available from: http://data.worldbank.org/indicator/NY.GDP.PCAP.CD. Accessed October 20, 2014.

14. Severens JL, Milne RJ. Discounting health outcome in economic evaluation; the ongoing debate. Value Health. 2004;7(4):397-401.

15. Drummond $M$, Barbieri $M$, Cook J, et al. Transferability of economic evaluations across jurisdictions: ISPOR Good Research Practices Task Force report. Value Health. 2009;12(4):409-418.

16. Ministry of Health of Ukraine. Реєстр оптово-відпускних цін на лікарські засоби [Register of the wholesale drug prices]. Available from: http://www.moz.gov.ua/ua/portal/register_prices_drugs/. Accessed June 6, 2014. Ukrainian.

17. Ukrainian state statistics department. Індекси споживчих цін на окремі групи товарів та послуг (до попереднього місяця). [Indexes of consumption prices for the separate groups of goods and services (related to the previous month)]. Ukrainian state statistics department. Available from http://www.km.ukrstat.gov.ua/ukr/statinf/ct/isc pm13.htm. Accessed October 20, 2014. Ukrainian.

18. Beusterien KM, Davies J, Leach M, et al. Population preference values for treatment outcomes in chronic lymphocytic leukaemia: a crosssectional utility study. Health Qual Life Outcomes. 2010;8:50.

19. State Committee of Statistics of Ukraine. Соціальний захист населення України. Статистичний збірник. [Social protection of the population of Ukraine. The compendium of statistics]. State Committee of Statistics of Ukraine: Kyiv; 2011. Ukrainian.

20. USA Social Security. Actuarial life table. Period life table, 2010. USA Social Security. Available from: http://www.ssa.gov/oact/STATS/ table4c6.html. Accessed April 22, 2015.
Cancer Management and Research

\section{Publish your work in this journal}

Cancer Management and Research is an international, peer-reviewed open access journal focusing on cancer research and the optimal use of preventative and integrated treatment interventions to achieve improved outcomes, enhanced survival and quality of life for the cancer patient The journal welcomes original research, clinical \& epidemiological

\section{Dovepress}

studies, reviews \& evaluations, guidelines, expert opinion \& commentary, case reports \& extended reports. The manuscript management system is completely online and includes a very quick and fair peerreview system, which is all easy to use. Visit http://www.dovepress.com/ testimonials.php to read real quotes from published authors. 